\title{
QUAL O LUGAR EPISTEMOLÓGICO DA PSICANÁLISE?
}

\author{
WHAT IS THE EPISTEMOLOGICAL PLACE OF PSYCHOANALYSIS? \\ ¿QUÉ LUGAR EPISTEMOLÓGICO OCUPA EL PSICOANÁLISIS?
}

\author{
Flávio Fernandes Fontes ${ }^{*}$ \\ André Luis Leite de Figueirêdo Sales ${ }^{* *}$
}

\begin{abstract}
RESUMO
Analisamos uma posição epistemológica autoatribuída por alguns psicanalistas e a nomeamos como "Teoria da Singularidade Epistemológica Absoluta da Psicanálise" (TSEAP). Ela consiste na ideia de que a psicanálise não é espécie de nenhum gênero; não é ciência, não é filosofia, não é arte, etc. Examinamos diferentes justificações para a TSEAP: 1) a descoberta de um objeto inédito na história do saber: o inconsciente; 2) a invenção de um novo método: a associação livre; 3 ) a invenção de um novo método de produção de conhecimento: a metapsicologia. À luz da perspectiva dos estudos freudianos críticos, realizamos um exame crítico dessas justificativas e concluímos que nenhuma das justificativas se sustenta. Por fim, propomos uma formulação diferente: a psicanálise não deve ser concebida como uma espécie sem gênero, mas sim como uma espécie que pertence a vários gêneros diferentes.
\end{abstract}

Palavras-chave: Estudos freudianos críticos. Epistemologia. Crítica.

\begin{abstract}
An epistemological position is analyzed and named as Theory of the Absolute Epistemological Uniqueness of Psychoanalysis (TAEUP). It consists of the idea that psychoanalysis is not a species of any genre - it is not science, not philosophy, not art, etc. There are different reasons to justify TAEUP: 1) the discovery of a new object in the history of knowledge: the unconscious; 2) the invention of a new method: free association; 3) the invention of a new method of knowledge production: metapsychology. We carry out a critical examination of these arguments, from the perspective of Critical Freud Studies, concluding that none of the above reasons is enough to claim TAEUP. In light of a critical Freudian studies perspective, through a critical exam of these justifications, it can be concluded that none of the above reasons is sustained. Finally, we propose a different picture: psychoanalysis should not be conceived as a genderless species, but as a species belonging to several genres.
\end{abstract}

Keywords: Critical Freud studies. Epistemology. Criticism.

Texto recebido em 24 de abril de 2017 e aprovado para publicação em $1^{\circ}$ de março de 2018.

Doutor em Psicologia e bolsista do Programa Nacional de Pós-Doutorado (PNPD) na Universidade Federal do Rio Grande do Norte (UFRN). E-mail: flaviofontes@outlook.com

** Doutorando em Psicologia no Programa de Pós-Graduação em Psicologia da Universidade Estadual Paulista Júlio de Mesquita Filho, Campus Assis-SP; psicólogo. E-mail: andreluislfs@gmail.com 


\section{RESUMEN}

Analizamos una posición epistemológica auto otorgada por algunos psicoanalistas y la nombramos "Teoría de la Singularidad Epistemológica Absoluta del Psicoanálisis" (TSEAP). Ella consiste en la idea de que el psicoanálisis no es especie de ningún género - no es ciencia, no es filosofía, no es arte, etc. Examinamos diferentes justificaciones para la TSEAP: 1) el descubrimiento de un nuevo objeto en la historia del conocimiento: el inconsciente; 2) la invención de un nuevo método, la asociación libre; 3) la invención de un nuevo método de producción de conocimiento, la metapsicología. Llevamos a cabo un examen crítico de estas justificaciones a la luz de los Estudios Freudianos Críticos y concluimos que ninguna de ellas se sostiene. En conclusión, proponemos una formulación alternativa: el psicoanálisis no debe ser concebido como una especie sin género, sino más bien como una especie que pertenece a varios diferentes géneros.

Palabras clave: Estudios freudianos críticos. Epistemología. Crítica.

\section{INTRODUÇÃO}

$\mathrm{P}$ rocuramos aqui problematizar o lugar epistemológico da psicanálise. Para isso definimos e descrevemos uma posição radical sobre o tema, a qual julgamos equivocada e cujos fundamentos e razões analisaremos. Entendemos ser pertinente fazê-lo, pois pensamos que a manutenção dessa posição tende a ignorar ou desqualificar críticas que são dirigidas à psicanálise. Em seguida, proporemos uma forma alternativa para pensar o estatuto do saber psicanalítico, que nos parece mais capaz de dar conta da complexidade do problema.

Para explicar que concepção epistemológica radical é essa, usaremos o texto de Elia (1999), quando este anuncia:

Sustentamos que a psicanálise não constitui simplesmente um "saber" a mais, entre outros, a integrar o rol daquilo que, a partir de uma velha discussão de ares epistemológicos, seriam as ciências (da "natureza" ou da "cultura") ou o campo dos saberes ditos não científicos, pré-científicos, ou simplesmente indiferentes à cientificidade (Elia, 1999).

Podemos ler esse trecho da seguinte maneira: para Elia, a psicanálise não é uma ciência, não é um saber não científico, não é um saber pré-científico assim como também não é indiferente à cientificidade. Temos aqui uma argumentação que segue a linha do que foi nomeado por Sokal e Bricmont (1999) de estratégia nem/nem: 
Os defensores de Lacan [. . . ] inclinam-se a responder a essas críticas recorrendo a uma estratégia que iremos chamar de "nem/nem": esses textos não devem ser avaliados nem como ciência, nem como filosofia, nem como poesia, nem [...] Fica-se então diante daquilo que se poderia chamar um "misticismo laico" (pp. 47-48).

Beividas (2000) também descreveu fenômeno semelhante com a denominação de "trincheira apofática" (do grego apophasis, que significa negação). Tratarse-ia de uma tática argumentativa presente no campo dos estudos lacanianos, que consiste em não se fornecer uma definição positiva de um conceito, mas simplesmente dizer o que ele não é. Simanke (2016), por sua vez, apontou a existência de uma "retórica da radicalidade que insiste à exaustão em que tudo o que a teoria proponha seja 'radical', 'extremo', 'absoluto', 'subversivo', e assim por diante" (p. 15). Com base na estratégia do nem/nem, da trincheira apofática e da retórica da radicalidade, consideramos que poderíamos formular mais explicitamente uma posição epistemológica usualmente atribuída ao saber psicanalítico, denominando-a Teoria da Singularidade Epistemológica Absoluta da Psicanálise (TSEAP). O que a TSEAP afirma essencialmente é: a psicanálise não pode ser espécie de nenhum gênero.

Tal posição tem o efeito de impossibilitar qualquer crítica externa. Afinal, se ela não é uma filosofia, não é uma literatura, não é uma ciência, etc., não se pode cobrá-la em nada, e não podemos julgá-la com base em qualquer referencial que não seja o seu próprio; e então corremos o risco de entrar em um jogo de cartas marcadas, no qual há um eterno ritual de autoconfirmação. Como bem observou Simanke (2016):

Em suma, a comunidade dos psicanalistas e de seus simpatizantes cultivou, de forma predominante, o que se pode chamar de um princípio de imunidade epistêmica, a saber, a ideia de que a psicanálise só pode ser avaliada segundo seus próprios critérios e de que toda avaliação baseada num critério não psicanalítico é um erro categorial, quando não um atentado mal-intencionado à sua identidade e à sua autonomia (p. 15).

Entendemos que o princípio de imunidade epistêmica representa um risco, o de consolidar uma política de isolamento e anticomunicação que impede a pesquisa e a inovação resultantes do contato com outras áreas do saber. Mas criticar as possíveis consequências desse princípio deixaria em aberto a questão sobre se a TSEAP tem uma fundamentação teórica consistente ou não. Afinal, será epistemologicamente justificável a singularidade absoluta da psicanálise? 


\section{JUSTIFICATIVA 1: A DESCOBERTA DE UM OBJETO INÉDITO NA HISTÓRIA DO SABER: O INCONSCIENTE}

Uma das formas de justificar a TSEAP é sustentar que o inconsciente, objeto da psicanálise, seria algo completamente novo, sem precedentes na história da humanidade. Assim o fazem Palombini (1996), Lo Bianco (2003) e GarciaRoza (2009). Este último, depois de fazer uma revisão da História da Filosofia, passando por autores como Platão, Descartes, Kant, Hegel e Husserl, afirma:

Onde situar a psicanálise? A resposta pode ser: em nenhum lugar preexistente. A psicanálise teria, nesse caso, operado uma ruptura com o saber existente e produzido o seu próprio lugar. Epistemologicamente, ela não se encontra em continuidade com saber algum, apesar de arqueologicamente estar ligada a todo um conjunto de saberes sobre o homem que se formou a partir do século XIX [. . . ] seu começo, irredutível a qualquer origem estrangeira, é a produção do conceito de inconsciente que resultou numa clivagem da subjetividade (Garcia-Roza, 2009, p. 22).

Temos nesse breve histórico realizado por Garcia-Roza um recorte bastante seletivo da História da Filosofia: basta dizer que Carus, von Hartmann, Schopenhauer e Nietzsche não são citados. $\mathrm{O}$ capítulo seguinte, intitulado $A$ pré-história da psicanálise, é baseado principalmente na História da loucura de Foucault, o que deixa de fora boa parte da literatura relevante e especializada sobre o assunto, permitindo, assim, que o conceito de inconsciente apareça de forma súbita, como uma novidade na história do pensamento ocidental, inaugurando um lugar epistemológico.

Um exame mais cuidadoso da bibliografia relevante mostra, no entanto, que o inconsciente não é um objeto descoberto pela primeira vez por Freud (Ellenberger, 1970; Whyte, 1962). Para compreender essa descoberta, é necessário considerar no mínimo dois séculos de trabalhos (1700-1900), que mostram o surgimento da palavra "inconsciente" na Alemanha e Inglaterra do século XVIII, e seu uso crescente até se tornar um assunto corrente e amplamente debatido por volta de 1870-1880 (Whyte, 1962).

Como demonstrou Ellenberger (1970), várias noções muito caras à teoria psicanalítica foram antecipadas no período batizado por esse historiador como "primeira psiquiatria dinâmica" (1775-1900). Entre elas, destacamos:

1) dipsiquismo e polipsiquismo, ou seja, o conceito de que a mente humana pode ser dividida em duas ou mais partes;

2) a psicogênese de doenças mentais e físicas; 
3) a teoria fluídica, isto é, a noção de forças psicológicas ou energia nervosa;

4) ideodinamismo, isto é, o movimento de ideias, inclusive inconscientes.

Tudo isso leva Ellenberger a afirmar que não houve uma revolução, mas sim uma transição gradual entre o período da "primeira psiquiatria dinâmica" e o período posterior das novas teorias psicanalíticas. Não por acaso, Sulloway (1979) coloca a ideia de que Freud teria descoberto o inconsciente como um dos vários mitos que sustentam outro: o de Freud como um herói de absoluta originalidade. ${ }^{1}$

Algo dessa preexistência do inconsciente é trazido à tona por Palombini (1996), quando nos lembra que Freud atribui aos experimentos hipnóticos a demonstração da existência do inconsciente. $\mathrm{O}$ trecho em questão é o seguinte: "Incidentalmente, mesmo antes da época da psicanálise, as experiências com a hipnose, especialmente a sugestão pós-hipnótica, já tinham demonstrado tangivelmente a existência e o modo de operação do inconsciente mental" (Freud 1915 b/2006, p. 174) ${ }^{4}$. É no mínimo estranho que Palombini não perceba que a existência do inconsciente antes de Freud é uma informação que deveria alterar o raciocínio de que a especificidade epistemológica da psicanálise seria devida a uma suposta descoberta do inconsciente!

Não se trata aqui de negar que o aparato conceitual erigido por Freud trouxe contribuiçôes importantes para nossa compreensão do inconsciente. Podemos citar como exemplos a discussão sobre o manejo da transferência (Freud, 1912/2006, 1915a/2006), a teoria das pulsóes (Freud 1905/2006, 1915c/2006, 1920/2006) e a própria compreensão do inconsciente como um sistema (Freud, 1915b/2006). No entanto, o que gostaríamos de enfatizar aqui é que essas contribuições se inserem em uma tradição histórica muito mais ampla de pesquisas (Ellenberger, 1970; Sulloway, 1979; Whyte, 1962), e que, por isso mesmo, não é possível justificar uma singularidade epistemológica absoluta para a psicanálise com base no caráter supostamente inédito do inconsciente.

\section{JUSTIFICATIVA 2: A INVENÇÃO DE UM MÉTODO: A ASSOCIAÇÃO LIVRE}

Outra justificativa para a TSEAP é a criação de um método de pesquisa. A associação livre é um método novo na história (embora tenha precedentes importantes, ela só passa a ser usada de forma mais sistemática por Freud, segundo Ellenberger, 1970), e pode ser visto tanto como um método terapêutico

\footnotetext{
${ }_{2}^{1}$ Ver Fierro (2016) e Fierro e Blume (2016) para ampla bibliografia crítica sobre a história da psicanálise.

2 A primeira data indica o ano de publicação original da obra e a segunda data indica a edição consultada pelo autor, que só será pontuada na primeira citação da obra no texto. Nas seguintes será registrada apenas a data de publicação original.
} 
como de investigação, o que torna essa justificativa promissora e aparentemente consistente. Apenas aparentemente, no entanto, pois veremos que ela não resiste a um exame mais cuidadoso.

Imaginemos que um pesquisador contemporâneo invente um microscópio que permita a observação de estruturas nunca descritas. Isso o levaria a dizer que suas descobertas não têm nada a ver com a Física nem com a Biologia? O absurdo dessa reivindicação é evidente. Da mesma forma, se Freud elabora um método clínico de pesquisa e tratamento, em nenhum momento fica claro por que ele deveria se situar "completamente fora" de outras áreas do saber por causa disso.

A comparação com o microscópio é feita pelo próprio Freud (1940b/2006, p. 211), que também afirma claramente que considera a psicanálise uma parte da Psicologia. Sua declaração mais explícita nesse sentido está em um texto da mesma época, no qual diz: "A psicanálise constitui uma parte da ciência mental da psicologia. [. . .] Também a psicologia é uma ciência natural. O que mais pode ser?" (Freud, 1940a/2006, p. 302).

A identidade da psicanálise como parte das Ciências Naturais está relacionada com a formação positivista de Freud (Fulgencio, 2016) e concorda com sua declaração explícita de filiação a uma visão de mundo científica (Freud, 1933/2006). Por mais que Freud aponte para as limitaçôes de uma psicologia da consciência, ele não está defendendo que, ao explorar o inconsciente, estamos saindo do terreno da Psicologia, mas sim ampliando seu escopo. O inconsciente, para Freud, é psíquico, carregando todas as ressonâncias de significado que o termo "psique" tem na cultura grega (Bettelheim, 2002).

Um novo método, portanto, não implica necessariamente a uma nova área de pesquisa, um novo objeto ou uma nova epistemologia de base, o que dificulta seu uso como justificativa para uma posição epistemológica singular da psicanálise. Tanto é assim que é possível para Freud ver a psicanálise como parte da Psicologia, tendo a Psique como objeto e guiando-se por uma visão de mundo científica.

Mas a comparação da associação livre com o microscópio apresenta problemas bem mais complexos, que exigem nossa atenção. Na situação de entrevista psicanalítica o terapeuta reage ao discurso do paciente, influenciando a direção de sua fala. O psicanalista Marmor (apud Eysenck, 1993, p. 105) escreve:

Dependendo do ponto de vista do analista, os pacientes de cada escola parecem contribuir exatamente com o tipo de dados fenomenológicos que confirmam as teorias e interpretações de seus analistas! Assim, cada teoria tende a se autojustificar. Os freudianos obtêm material sobre o complexo de Édipo e a angústia de castração, os junguianos, sobre os arquétipos, os rankianos, sobre a angústia de separação, os 
adlerianos, sobre as lutas e sentimentos de inferioridade masculinos, os horneyanos, sobre as imagens idealizadas, os sullivanianos, sobre os distúrbios de relações interpessoais, e assim por diante. $\mathrm{O}$ fato é que numa transação tão complexa quanto o processo terapêutico psicanalítico, o impacto exercido pelo paciente sobre o terapeuta e sobretudo deste sobre aquele é inusitadamente profundo. Os elementos pelos quais o analista demonstra interesse, o tipo de perguntas que faz, o tipo de dados aos quais reage ou que prefere ignorar e as interpretações a que procede são coisas que exercem um impacto sutil, mas significativamente sugestivo sobre o paciente, levando-o a dar preferência a exteriorização de certos dados e não de outros.

Em seu longo estudo sobre Freud, Macmillan (1997) reforça essa ideia ao concluir que o método psicanalítico não é capaz de gerar fatos clínicos com consenso. Seus resultados são tão variáveis que é preciso dizer que a associação livre não descobre fenômenos, mas sim cria seus próprios dados. A definição do que vai ser descoberto pela associação livre vai ser dada em grande parte pelo referencial teórico de quem escuta e comanda as intervençóes segundo expectativas e conceitos já elaborados.

Aparentemente, foi por acreditar que o método da associação livre é homogêneo e produtor de resultados consistentes que os psicanalistas passaram a acreditar no papel imprescindível da clínica para confirmação e elaboração das suas teorias. No entanto, se essa confiabilidade e consistência do método somente se mantêm se ele for operado por psicanalistas com formação teórica similar, então a associação livre talvez seja mais bem descrita como uma fábrica de dados por encomenda para a teoria de quem opera o setting analítico.

Macmillan (1997) e Grünbaum (1984) já chamaram a atenção para esse problema, ao colocarem que a associação livre é um método "contaminado" pelas sugestóes do terapeuta para o paciente. Se a principal característica desse método freudiano é sua enorme elasticidade e capacidade de se transformar para produzir resultados compatíveis com quase qualquer teoria e interpretação que se possa formular, dificilmente isso pode ser contado como um elemento que ajude a definir a especificidade epistemológica da psicanálise.

\section{JUSTIFICATIVA 3: UMA NOVA FORMA DE PRODUÇÃO DO CONHECIMENTO: A METAPSICOLOGIA}

Se Freud contribui com ideias inovadoras e inéditas sobre o inconsciente como objeto de pesquisa, isso tampouco é suficiente para defender a TSEAP. Ao propor uma teoria diferente para um objeto já existente, nenhum cientista se coloca fora da Ciência, nenhum filósofo fora da Filosofia, e assim por diante. Assim, não há razões para acreditar que, ao criar teorias, Freud teria inventado um limbo 
que não deve responder nem a Ciência, nem a Filosofia, nem a Mitologia, nem a nada.

Estaria a diferença não em um novo conteúdo teórico, mas sim em um novo método de produção do conhecimento e construção conceitual? Palombini (1996) defende que o método de elaboração conceitual da metapsicologia é específico da psicanálise. Resta saber por que motivos ele deveria ser considerado como tal, já que consiste em especulação teórica baseada em observações (Fulgencio, 2008, 2016).

Qual método estaria por trás da utilização e criação de conceitos tão diferentes como os de defesa, repressão, transferência, pulsão, narcisismo, zonas erógenas, libido, pulsão de morte, ideal do eu, etc.? Será possível derivar todos esses conceitos com base em um método que não seja a especulação? Se houvesse tal método psicanalítico, seria possível avaliar todas as produções teóricas conflitantes que vieram depois de Freud e saber exatamente quais seguem seu método e quais não seguem. Como qualquer pessoa familiarizada com a literatura psicanalítica sabe, esse conjunto de critérios metodológicos é de difícil obtenção, dado que formulações completamente diferentes podem ser criadas, todas com base na obra de Freud e com "dados" provenientes da clínica em seu apoio.

Concluímos, assim, que Freud nunca especificou regras de um suposto método de produção de conhecimento psicanalítico, mas apenas produziu tal conhecimento em ato, por meio de sucessivas reformulações ao longo de sua obra. Essa postura flexível e não dogmática com relação ao método de produção de conhecimento se faz presente na seguinte afirmação: "A meu ver, é lícito darmos livre curso a nossas especulações, desde que preservemos a frieza de nosso juízo, e não tomemos os andaimes pelo edifício" (Freud, 1900/2006, p. 567). O fato de que não existe nenhum acordo sobre o que deve ser legitimamente considerado psicanálise mostra que tampouco se pode inferir um método implícito na obra de Freud com uma mínima margem de consenso.

Defendemos que é preciso reconhecer que o procedimento freudiano é, basicamente, especulativo e empírico. Ora realiza construçōes teóricas que se afastam consideravelmente das observações, ora refina conceitos que buscam apoio e validação nessas mesmas observações oriundas da clínica. Afirmar o caráter especulativo e empírico das proposições freudianas não é, de forma alguma, desvalorizá-las (não se trata aqui de contrapor o método especulativo ao método experimental, para, em seguida, colocar determinada concepção de ciência como parâmetro único de produção do conhecimento válido). Significa apenas que sua forma de produção do conhecimento não é diferente o bastante 
daquela realizada por outros filósofos, teóricos e cientistas de sua época, ao ponto de justificar a pretensão de uma singularidade epistemológica absoluta.

\section{UMA VISÃO ALTERNATIVA: O PERTENCIMENTO A VÁRIOS GÊNEROS}

Vejamos então como podemos elaborar uma visão epistemológica mais congruente com a complexidade real da psicanálise. Pensamos que é mais produtivo postular a existência de uma forte interseção entre os domínios da Arte, da Ética e da Ciência ${ }^{3}$ na psicanálise, uma infusão presente desde o início, visto que a obra de Freud participa de todos esses registros. ${ }^{4}$ Gellner (1988) resume em uma frase vários aspectos a serem levados em conta: "A psicanálise é uma teoria, uma técnica, uma organização, uma linguagem, um ethos, uma ética, um clima” (p. 14). Ao longo da história da psicanálise, a maneira como esses vários registros se misturam parece ter alimentado a polêmica e a discussão. Distingui-los pode ser útil para a melhoria da qualidade dos debates.

A TSEAP estaria correta se fosse enunciada assim: a psicanálise não é somente uma ciência, não é somente uma filosofia etc., no sentido de que a psicanálise não pode ser reduzida à Ciência, ou à Filosofia, etc. No entanto defendemos que isso acontece porque a psicanálise é uma "mistura" de várias áreas ou categorias epistemológicas (Ciência, Filosofia, Literatura, Mitologia, religião, etc.) e não porque ela inaugura uma epistemologia.

Dito de outra forma: estando "o problema da incidência do significante social sobre o indivíduo" (Guattari, 2004, p. 89) colocado em todos os instantes da existência humana e sendo passível de abordagem mediante múltiplos campos de produção de conhecimento, é legítimo localizar a singularidade epistemológica da psicanálise em uma multiplicidade de epistemes com as quais e pelas quais esta pode ser pensada.

O leitor pode se perguntar: mas uma mistura de áreas e formas de saber já existentes não gera uma epistemologia nova? Por que pensar em dividir analiticamente essas categorias? Sua tensão não configura um todo, cuja unicidade deve ser respeitada? Como resposta a essas perguntas, entendemos que cada uma das áreas citadas acima tem critérios e debates internos, uma história, conteúdo específico. Ao pretender ser uma tradição completamente nova, a psicanálise da TSEAP recua diante de conteúdos potencialmente enriquecedores para a própria psicanálise e age como se não precisasse e não se relacionasse com nenhuma dessas discussões.

\footnotetext{
${ }^{3}$ Esferas culturais de valor que, para Habermas (2000), diferenciaram-se na Modernidade. ${ }^{4}$ Ver, nesse sentido, Rieff (1995).
} 
Ao agir assim, tal psicanálise participa de tais categorias epistemológicas sem qualquer reflexão, de forma inconsciente. $O$ resultado disso somente pode ser desastroso: se a psicanálise não reconhece a natureza híbrida dos seus fundamentos, ela estará fadada a ser uma filosofia sem o saber, uma mitologia sem o saber; em suma, um caldeirão epistemológico inconsciente de si.

Ao distinguir áreas epistemológicas, só temos a ganhar em poder de análise, precisão e crítica dos conceitos. A produção do conhecimento que segue tais distinções avança com muito mais rigor e exatidão, pois expõe as questões de forma mais específica e completa, enquanto uma produção do conhecimento que mistura categorias de forma desavisada tende a causar confusão, superficialidade e debates infrutíferos.

A discussão sobre a psicanálise terá sempre que se servir de muitas áreas diferentes, e isso se torna ainda mais evidente, visto que a própria reflexão psicanalítica extrapolou, há muito tempo, os limites de sua preocupação clínica inicial. Será preciso recorrer à História e à Antropologia para a discussão de Totem e tabu (Freud, 1913), à hermenêutica para a discussão da interpretação em suas várias aplicações (obras de arte, sintomas neuróticos, sonhos, etc.), à Filosofia e à religião para discussão de textos como $O$ mal-estar na civilização (Freud, 1930/2006) e O futuro de uma ilusão (Freud, 1927/2006), e assim por diante.

O que caracteriza a TSEAP é utilizar a estratégia do nem/nem para cortar relaçóes com os demais campos do saber e declarar uma independência extremamente exagerada da psicanálise, o que acaba resultando em uma espécie de ensimesmamento epistemológico. Como tal proposta não apresenta nenhum fundamento sólido ou justificativa consistente, somente podemos concluir que a TSEAP não passa de uma ideologia que visa a promover a psicanálise como algo especial, totalmente sem precedentes.

Como já vimos, uma das funções dessa concepção é tornar a psicanálise inacessível a qualquer crítica. Mas é preciso acrescentar ainda uma segunda função: fazer com que os psicanalistas tenham a ideia de pertencer a uma elite, a um grupo escolhido, completamente único, que tem acesso a um saber especial (Weisz, 1975). O próprio Freud advertiu contra a tendência de fazer da psicanálise uma Weltanschauung (visão de mundo) (Freud, 1933). Contudo tal advertência não foi suficiente para impedir que muitos psicanalistas assim a tomassem, como ressaltam Roustang (1987) e Sulloway (1979). Para o último, "Poucas teorias na ciência geraram discípulos como o movimento psicanalítico, nas suas manifestaçôes semelhantes a um culto, na sua militância, e na aura de religião que o permeou" (Sulloway, 1979, p. 480). 
O problema é que, para manter o status de um "saber especial", a TSEAP falseia a história das ideias (ao sugerir que o inconsciente teria surgido com Freud), faz filosofia de má qualidade (ao negar o uso do método especulativo, falhar em distinguir entre diferentes epistemologias básicas e tentar inventar uma epistemologia sem justificação consistente) e oculta seus procedimentos de mistificação. A TSEAP é uma defesa irracional da causa psicanalítica, que é alçada a uma posição privilegiada e intocável, mantendo-se, assim, pela recusa de examinar criticamente a própria mitologia.

Fica claro, pela nossa descrição, que a TSEAP é uma posição extremamente radical, mas tememos que ela seja muito mais comum do que possa parecer. Ao contrário do que prega o isolacionismo da TSEAP, a psicanálise pode e deve estabelecer diálogo com a Ciência, a Filosofia, a Antropologia, a Literatura, etc., visto que participa desses campos. Afinal, "Essa redução do diálogo com outros campos tem efeitos nefastos para a saúde da psicanálise. Uma disciplina que se isola perde a abertura, o oxigênio e o distanciamento que a troca com os outros proporciona" (Dupont, 2014, pp. 77-78).

A provocação feita em torno dos riscos decorrentes da TSEAP não nos parece contrariar o espírito de criação da psicanálise, fundada por um cientista poeta que não se cansava de buscar palavras, na Neurologia, na Literatura e na Mitologia, para dar passagem àquilo que via. Ao ousar compor relações improváveis entre campos distintos, Freud interpelou a noção de desejo, de ciência e de racionalidade de seu tempo. É fundamental, para a renovação da psicanálise, que esta possa reinventar a si mesma em permanente interação com as mudanças da sociedade e do saber, evitando o risco de se enclausurar na repetição de verdades dogmáticas e com pretensões universais (Dupont, 2014).

Para a TSEAP, a psicanálise não participa de nenhum campo, a não ser o próprio. É uma categoria absolutamente nova, o que a faz parecer a única habitante de uma ilha deserta, distante de qualquer continente conhecido. O que tal necessidade de isolamento parece revelar é o medo da crítica e o pavor de que tal contato revele as fragilidades de uma teoria extremamente ambiciosa a ponto de reinterpretar praticamente toda a cultura humana (atividade intelectual, arte, moral e religião), mas que não suporta ser questionada.

Dito isso, a TSEAP passa muito perto de acertar (a psicanálise não cabe mesmo dentro de um só gênero). Por isso propomos uma modificação da frase "a psicanálise não pode ser espécie de nenhum gênero" para outra que nos parece mais promissora, pela abertura que proporciona: "a psicanálise não pode ser concebida como espécie de um só gênero e sim de vários”. 
Foge ao escopo deste trabalho abordar como as especificidades da psicanálise contribuem na interlocução com os gêneros dos quais participa. Nosso intuito foi circunscrever, clara e concisamente, aquilo que acreditamos ser um entrave ao desenvolvimento de investigações que se ocupem do lugar epistemológico da psicanálise, fornecendo, ao mesmo tempo, uma proposta para a reformulação do problema. Por fim, esclarecemos que a TSEAP aqui descrita não coincide com a posição de Freud nem pode ser vista como representativa de todos os psicanalistas, em sua heterogeneidade de orientações, retóricas e possíveis atravessamentos ideológicos. Sua presença no meio psicanalítico, no entanto, pareceu-nos suficientemente relevante para mobilizar a escrita deste artigo. 


\section{REFERÊNCIAS}

Beividas, W. (2000). Inconsciente et verbum: psicanálise, semiótica, ciência, estrutura. São Paulo: Humanitas.

Bettelheim, B. (2002). Freud e a alma humana. Á. Cabral (Trad.). São Paulo: Cultrix.

Dupont, S. (2014). L'autodestruction du mouvement psychanalytique. Paris: Gallimard.

Elia, L. (1999). A transferência na pesquisa em psicanálise: lugar ou excesso? Psicologia: Reflexão e Crítica, 12(3). Recuperado a partir de http://www.scielo. br/scielo.php?script=sci_arttext\&pid=S0102-79721999000300015\&lng=en $\&$ nrm $=$ iso

Ellenberger, H. F. (1970). The discovery of the unconscious: the history and evolution of dynamic psychiatry. New York: Basic Books.

Eysenck, H. H. (1993). Decadência e queda do império freudiano. C. Marques (Trad.). Rio de Janeiro: Civilização Brasileira.

Fierro, C. (2016). Políticas psicoanalíticas (I): controversias en la historiografía del Movimiento Psicoanalítico desde la Sociología del Conocimiento y los Estudios Sociales de la Ciencia. Psiencia: Revista Latinoamericana de Ciencia Psicológica, 8(2), 1-74. Recuperado a partir de https://www.redalyc.org/ pdf/3331/333147069004.pdf

Fierro, C., \& Blume, L. B. (2016). Políticas psicoanalíticas (II): las controversias en la Historia del Movimiento Psicoanalítico desde el Programa Empírico del Relativismo de los Estudios Sociales de la Ciencia. Psiencia: Revista Latinoamericana de Ciencia Psicológica, 8(3), 1-66. Recuperado a partir de http://www.psiencia.org/ojs/index.php/psiencia/article/view/207

Freud, S. (1900/2006). A interpretação dos sonhos. In J. Salomão (Trad.), Edição standard brasileira das obras psicológicas completas de Sigmund Freud. (Vol. 5, pp. 371-650). Rio de Janeiro: Imago, 2006. (Publicado originalmente em 1900).

Freud, S. (1905/2006). Três ensaios sobre a teoria da sexualidade. In J. Salomão (Trad.), Edição standard brasileira das obras psicológicas completas de Sigmund Freud. (Vol. 7, pp. 117-229). Rio de Janeiro: Imago, 2006. (Publicado originalmente em 1905). 
Freud, S. (1912/2006). A dinâmica da transferência. In J. Salomão (Trad.), Edição standard brasileira das obras psicológicas completas de Sigmund Freud. (Vol. 12, pp. 107-120). Rio de Janeiro: Imago, 2006. (Publicado originalmente em 1912).

Freud, S. (1913/2006). Totem e tabu. In J. Salomão (Trad.), Edição standard brasileira das obras psicológicas completas de Sigmund Freud. (Vol. 13, pp. 11162). Rio de Janeiro: Imago, 2006. (Publicado originalmente em 1913).

Freud, S. (1915a/2006). Observações sobre o amor transferencial. In J. Salomão (Trad.), Edição standard brasileira das obras psicológicas completas de Sigmund Freud. (Vol. 12, pp. 173-188). Rio de Janeiro: Imago, 2006. (Publicado originalmente em 1915).

Freud, S. (1915b/2006). O inconsciente. In J. Salomão (Trad.), Edição standard brasileira das obras psicológicas completas de Sigmund Freud. (Vol. 14, pp. 163222). Rio de Janeiro: Imago, 2006. (Publicado originalmente em 1915).

Freud, S. (1915c/2006). Os instintos e suas vicissitudes. In J. Salomão (Trad.), Edição standard brasileira das obras psicológicas completas de Sigmund Freud. (Vol. 14, pp. 115-144). Rio de Janeiro: Imago, 2006. (Publicado originalmente em 1915).

Freud, S. (1920/2006). Além do princípio do prazer. In J. Salomão (Trad.), Edição standard brasileira das obras psicológicas completas de Sigmund Freud. (Vol. 18, pp. 11-76). Rio de Janeiro: Imago, 2006. (Publicado originalmente em 1920).

Freud, S. (1927/2006). O futuro de uma ilusão. In J. Salomão (Trad.), Edição standard brasileira das obras psicológicas completas de Sigmund Freud. (Vol. 21, pp. 11-63). Rio de Janeiro: Imago, 2006. (Publicado originalmente em 1927).

Freud, S. (1930/2006). O mal-estar na civilização. In J. Salomão (Trad.), Edição standard brasileira das obras psicológicas completas de Sigmund Freud. (Vol. 21, pp. 65-148). Rio de Janeiro: Imago, 2006. (Publicado originalmente em 1915).

Freud, S. (1933/2006). Conferência XXXV: a questão de uma Weltanschauung. In J. Salomão (Trad.), Edição standard brasileira das obras psicológicas completas de Sigmund Freud. (Vol. 22, pp. 155-177). Rio de Janeiro: Imago, 2006. (Publicado originalmente em 1933).

Freud, S. (1940a/2006). Algumas lições elementares de psicanálise. In J. Salomão (Trad.), Edição standard brasileira das obras psicológicas completas de Sigmund 
Freud. (Vol. 23, pp. 297-306). Rio de Janeiro: Imago, 2006. (Publicado originalmente em 1940).

Freud, S. (1940b/2006). Esboço de psicanálise. In J. Salomão (Trad.), Ediçãao standard brasileira das obras psicológicas completas de Sigmund Freud. (Vol. 23, pp. 151-221). Rio de Janeiro: Imago, 2006. (Publicado originalmente em 1940).

Fulgencio, L. (2008). O método especulativo em Freud. São Paulo: EDUC.

Fulgencio, L. (2016). Freud \& Mach: influências e paráfrases. São Paulo: Concern, FAPESP.

Garcia-Roza, L. A. (2009). Freud e o inconsciente. (24a ed.). Rio de Janeiro: Jorge Zahar.

Gellner, E. (1988). O movimento psicanalítico. Á. Cabral (Trad.). Rio de Janeiro: Jorge Zahar.

Grünbaum, A. (1984). The foundations of psychoanalysis: a philosophical critique. Berkeley: University of California Press.

Guattari, F. (2004). A transversalidade. In Psicanálise e transversalidade: ensaios de análise institucional. (pp. 88-105). Aparecida: Ideias \& Letras.

Habermas, J. (2000). O discurso filosófico da Modernidade. L. S. Repa, \& R. Nascimento (Trad.). São Paulo: Martins Fontes.

Lo Bianco, A. C. (2003, julho-dezembro). Sobre as bases dos procedimentos investigativos em psicanálise. Psico-USF, 8(2), 115-123. Recuperado a partir de http://www.scielo.br/pdf/pusf/v8n2/v8n2a03.pdf

Macmillan, M. (1997). Freud evaluated: the completed arc. Cambridge: MIT Press.

Palombini, A. L. (1996). Fundamentos para uma crítica da epistemologia da psicanálise. (Dissertação de Mestrado). Instituto de Filosofia e Ciências Humanas, Pós-Graduação em Filosofia, Universidade Federal do Rio Grande do Sul, Porto Alegre. Recuperado a partir de http://www.lume.ufrgs.br/ bitstream/handle/10183/10282/000146231.pdf?sequence $=1$

Rieff, P. (1995). Freud: the mind of the moralist. ( $3^{\text {a }}$ ed.). Chicago: Chicago University Press. 
Roustang, F. (1987). Um destino tão funesto. J. Bastos (Trad.). Rio de Janeiro: Taurus.

Simanke, R. T. (2016). Para além do princípio de imunidade epistêmica nos estudos psicanalíticos. In L. Fulgencio, Mach \& Freud: influências e paráfrases. (pp. 13-22). São Paulo: Concern.

Sokal, A., \& Bricmont, J. (1999). Imposturas intelectuais. M. Altman (Trad.). Rio de Janeiro: Record.

Sulloway, F. J. (1979). Freud, biologist of the mind: beyond the psychoanalytic legend. New York: Basic Books.

Weisz, G. (1975). Scientists and sectarians: the case of psychoanalysis. Journal of the History of the Behavioral Sciences, 11(4), 350-364.

Whyte, L. L. (1962). The unconscious before Freud. New York: Anchor Books. 